\title{
Considerações teóricas sobre governança corporativa no terceiro setor à luz da teoria da agência
}

\author{
ADONAI JOSÉ LACRUZ ${ }^{12}$

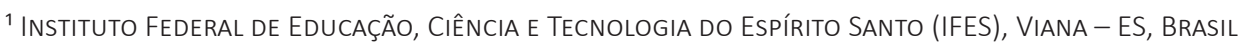 \\ ${ }^{2}$ Universidade Federal do Espírito Santo (UFES) / Programa de Pós-Graduação em AdministraçÃo, VItória - ES, Brasil
}

\begin{abstract}
Resumo
Apresenta-se neste artigo uma revisão da literatura sobre governança corporativa em Organizações Não Governamentais (ONGs) sob a perspectiva analítica da teoria da agência, em especial alinhando os conceitos ao contexto do terceiro setor brasileiro e à relação de agência na qual o doador (principal) contrata a ONG (agente) para o desenvolvimento de projeto por meio da doação de recursos vinculados. Espera-se, com isso, contribuir para o melhor entendimento da relação entre ONGs e doadores e para o desenvolvimento de futuras pesquisas. Os fundamentos da teoria da agência são muitas vezes abordados de forma incompleta, quando a governança corporativa é sobreposta ao contexto do terceiro setor. Assim, foram extrapolados os pressupostos e conceitos para o ambiente do terceiro setor no Brasil. Como resultados podem-se destacar a proposição de que o pressuposto da incompatibilidade de horizontes de planejamento entre principal (doador) e agente (ONG) ocorre de forma inversa no terceiro setor ao assumido como regra geral para organizações empresariais e o reconhecimento de custos de agência relacionados às perdas residuais, dos quais decorrem problemas de agência de natureza propriedade x gestão também no ambiente do terceiro setor. Assim, a estruturação da governança corporativa no terceiro setor sob a perspectiva da teoria da agência permitiu formular relações que complementam as generalidades da teoria, contribuindo para o melhor entendimento da sua aplicação, bem como para a proposição de uma agenda de pesquisa.
\end{abstract}

Palavras-chave: Governança corporativa. Teoria da agência. Terceiro setor. Organização Não Governamental.

\section{Theoretical considerations on corporate governance in the third sector in the agency theory perspective}

\begin{abstract}
This article presents a literature review on corporate governance of Non-Governmental Organizations (NGOs) using the agency theory approach, especially aligned to the context of the Brazilian third sector, considering NGO (agent) contracting by the donor (principal) for sponsored projects development. The aim is to understand the relationship between NGOs and donors and contribute to the development of future research. The fundamentals of agency theory are often incompletely addressed by overlapping corporate governance with the context of the third sector. The assumptions and concepts of agency theory were extrapolated for the Brazilian third sector. As a result, it is possible to say that the mismatch of planning horizons between the principal (donor) and agent (NGO) occurs inversely when comparing the phenomenon in the third sector with the general rule observed in business organizations. Also, the study identified that there are agency costs related to residual losses in the third sector, originating problems of property agency versus property management. The structuring of corporate governance in the third sector from the agency theory perspective allowed the formulation of relations that complement the generalities of the theory, contributing to better understand its application and to propose a research agenda.
\end{abstract}

Keywords: Corporate governance. Agency theory. Third sector. Non-governmental organization.

\section{Consideraciones teóricas sobre la gobernanza corporativa en el tercer sector desde la perspectiva de la teoría de la agencia}

\section{Resumen}

En este estudio teórico se presenta una revisión de literatura sobre la gobernanza corporativa de las organizaciones no gubernamentales (ONG) desde la perspectiva de la teoría de la agencia, especialmente alineando los conceptos con el contexto del tercer sector brasileño y la contratación de la ONG (agente) por parte del donante (principal) para el desarrollo de proyectos patrocinados, con el fin de comprender la relación entre las ONG y los donantes y contribuir al desarrollo de futuras investigaciones. Los fundamentos de la teoría de la agencia a menudo se abordan de manera incompleta al superponer la gobernanza corporativa al contexto del tercer sector. Los supuestos y conceptos de la teoría de la agencia se extrapolaron al entorno del tercer sector en Brasil. Como resultado, se puede destacar que la suposición de la incompatibilidad entre los horizontes de planificación entre el principal (donante) y el agente (ONG) se produce de manera inversa en el tercer sector a lo asumido como regla general para las organizaciones empresariales y el reconocimiento de los costos de la agencia relacionados con las pérdidas residuales, de los cuales surgen problemas de agencia de naturaleza de propiedad contra gestión también en el contexto del tercer sector. La estructuración de la gobernanza corporativa en el tercer sector desde la perspectiva de la teoría de la agencia permitió la formulación de relaciones que complementan las generalidades de la teoría, contribuyendo a una mejor comprensión de su aplicación y proponiendo una agenda de investigación.

Palabras clave: Gobernanza corporativa. Teoría de la agencia. Tercer sector. Organización no gubernamental. 


\section{INTRODUÇÃO}

O tema governança corporativa - desse ponto em diante, apenas governança - tem sido muito explorado em estudos aplicados a Organizações Não Governamentais (ONGs). Para compreender a relevância da governança no contexto do terceiro setor, é preciso refletir sobre o possível impacto sobre as ONGs. A premissa é de que, de um conjunto de ONGs, algumas diferenciem-se com "boa" governança. Essas ONGs, coeteris paribus, seriam consideradas mais atraentes para os doadores; consequentemente, receberiam mais recursos em doação. De forma geral, a discussão parte da hipótese de que os mecanismos de governança influenciam o desempenho organizacional (e.g. HASNAN, MOHAMAD, ZAINUDDIN et al., 2016).

A revisão da literatura sobre governança no terceiro setor revela análises de diferentes perspectivas teóricas, nas quais predomina a teoria da agência (RENZ e ANDERSSON, 2014; MARQUES, RODY, REINA et al., 2015).

Apesar da inegável contribuição de estudos anteriores, a reflexão sobre o alinhamento dos fundamentos da teoria da agência visando à sobreposição dos conceitos de governança no terceiro setor é pouco aprofundada (e.g. YETMAN e YETMAN, 2012; ÁVILA e BERTERO, 2016). De forma geral, os estudos abordaram de forma marginal os pressupostos da teoria da agência no contexto da governança no terceiro setor, limitando-se ao aspecto de diferentes funções e utilidade (e.g. HARRIS, PETROVITS e YETMAN, 2015).

Apesar de haver abundante literatura sobre governança no terceiro setor, é incipiente o entendimento das suas relações no contexto deste. Assim, objetivamente buscou-se preencher um pouco essa lacuna alinhando os fundamentos da governança à luz da teoria da agência ao contexto do terceiro setor brasileiro, a fim de ampliar o entendimento sobre a relação entre ONGs e doadores.

A investigação relacionada à governança no ambiente do terceiro setor no Brasil exige um recorte que favoreça comparar entidades mais homogêneas entre as próprias entidades desse setor, pois este contempla de forma abrangente as atividades da sociedade civil que não se enquadram nos denominados primeiro e segundo setores, como partidos políticos, associações e fundações privadas sem fins lucrativos, sindicatos, conselhos de classe, organizações religiosas etc. (IBGE, 2018). Assim, num nível abstrato, as unidades de análise escolhidas foram as associações e fundações privadas sem fins lucrativos comumente denominadas ONGs, pois suas características específicas as tornam semelhantes entre si e diferentes das demais (IPEA, 2018). Nesse contexto, extrapolam-se os pressupostos e conceitos da teoria da agência para o ambiente do terceiro setor brasileiro visando a discutir os conflitos existentes entre principal e agente, tendo como concreto a relação de agência observada na contratação da ONG (agente) pelo doador (principal) no repasse de doações.

\section{Breve Contextualização do Terceiro Setor no Brasil}

$\mathrm{Na}$ introdução, apresentou-se uma reflexão sobre governança no terceiro setor e se considerou a possibilidade de oferecer contribuições para o seu entendimento. A fim de subsidiar o objetivo formulado, apresenta-se um panorama geral desse setor no Brasil, que auxilia o processo de delimitação do objeto de análise.

Ao abordar o tema terceiro setor, é pertinente distinguir inicialmente os três setores de atividades econômicas da sociedade: as atividades estatais referem-se ao primeiro setor, representado pela Administração Pública; as atividades de mercado, ao segundo setor, representado pelas empresas com finalidade lucrativa; por sua vez, o terceiro setor contempla, de forma abrangente, as atividades da sociedade civil que não se enquadram nas dos demais setores. Em outra perspectiva, o primeiro setor opera recursos públicos para fins públicos; o segundo setor, recursos privados para fins privados; e o terceiro setor, recursos públicos e privados para fins públicos (FERNANDES, 1994).

Em 2016, as entidades sem fins lucrativos no Brasil representaram 9,5\% das empresas e outras organizações, com 6,8\% do pessoal ocupado total, 7,2\% do pessoal ocupado assalariado e $6,7 \%$ dos salários e outras remunerações pagos no ano (IBGE, 2018).

O estudo Perfil das Organizações da Sociedade Civil no Brasil (IPEA, 2018) faz um recorte das entidades sem fins lucrativos formais, inspirado nos estudos As Fundações Privadas e Associações sem Fins Lucrativos no Brasil, do Instituto de Pesquisa Econômica Aplicada e do IBGE; e Classification on the Purpose of Non-Profit Institutions Serving Households, da Organização das Nações Unidas (ONU). Nesse panorama, foram consideradas Organizações da Sociedade Civil (OSCs) as entidades sem fins lucrativos que se enquadrassem, simultaneamente, em cinco critérios: institucionalizadas, privadas, sem fins lucrativos, 
autoadministradas e voluntárias. No Brasil, dentro do Novo Código Civil (Lei n. 10.406/2002), há três figuras jurídicas que preenchem simultaneamente os cinco critérios: associações e fundações privadas sem fins lucrativos e organizações religiosas.

Na pesquisa realizada pelo IPEA (2018), do rol de entidades sem fins lucrativos, foi feita depuração com base nos cinco critérios expostos, excluindo-se caixas escolares e similares; partidos políticos; sindicatos, federações e confederações; condomínios; cartórios; sistema S; entidades de mediação e arbitragem; comissão de conciliação prévia; conselhos, fundos e consórcios municipais; e cemitérios e funerárias, revelando que em 2016 havia 820 mil OSCs inscritas no Cadastro Nacional da Pessoa Jurídica, da Secretaria da Receita Federal.

A origem das entidades do terceiro setor no Brasil é atribuída às comunidades eclesiais de base que nascem na década de 1960 e às entidades surgidas no âmbito do sistema internacional de cooperação para o desenvolvimento a partir da década de 1970, ambas com raízes numa tradição filantrópica (FERNANDES, 1997).

Na década de 1990, a concepção das entidades do terceiro setor foi fortemente influenciada pela agenda da Nova Administração Pública (NAP), que promoveu uma mudança de paradigma na filantropia (DANGINO, 2011). A abordagem tradicional de quase concessão de serviços sociais às entidades sem fins lucrativos, num ambiente não concorrencial, cedeu espaço para um ambiente no qual os doadores não atribuem contratos às entidades do terceiro setor pelo que elas são, mas pelo que são capazes de entregar (RYAN, 1999). Isso estendeu a responsabilidade externa das entidades do terceiro setor, que passaram a ser, cada vez mais, "obrigadas" a demonstrar desempenho em termos de eficiência e eficácia (SILVA, 2010) e a introduzir modelos de gestão com esse propósito (SMITH, 2010), especialmente para lidar com as restrições do mercado de doações (ALDASHEV e VERDIER, 2010).

Em síntese, a NAP promoveu a competição e gerou uma pressão no sentido de "profissionalizar" os métodos de gestão pela adoção dos princípios de negócio das organizações com fins lucrativos (EIKENBERRY e KLUVER, 2004), uma vez que as doações são feitas de forma consistente com os valores próprios dos doadores e orientadas a resultados mensurados pelos seus padrões (POZORSKI, 2000). As ONGs são, assim, conduzidas a práticas e procedimentos prevalecentes em organizações que constituem o mercado de doação; ou seja, as organizações públicas, empresariais e os institutos empresariais. Como o setor governamental foi fortemente influenciado pela agenda da NAP (GREILING e STÖTZER, 2015) e os institutos empresariais são constituídos por organizações empresariais, prevalece a lógica do mercado.

Assim, as pressões dos doadores no mercado de doação podem explicar, em certa medida, por que as organizações sem fins lucrativos vêm assumido modelos de gestão sob influência do mercado (SALAMON, 1997), entre eles a governança.

Esta breve caracterização do terceiro setor no contexto brasileiro revelou um ambiente bastante heterogêneo, apontando que a investigação que se pretende demanda uma delimitação empírica que favoreça a observação de entidades mais homogêneas entre si; objetivamente, neste estudo, as associações e fundações privadas sem fins lucrativos. Sugere, também, que a motivação para adoção de práticas de governança pelas entidades do terceiro setor decorra, em parte, das parcerias feitas com organizações empresariais, estatais, institutos empresariais e outras entidades do terceiro setor (decorrentes do processo de captação de recursos), pois desencadeiam arranjos organizacionais com o intuito de coordenar as atividades fruto das parcerias. Além disso, a competição mais intensa por recursos públicos e privados exerce força sobre a profissionalização dos processos de gestão das entidades do terceiro setor, dentre eles a adoção de práticas de governança, na busca por maior eficiência, o que as impulsiona a migrarem de um modelo filantrópico para um modelo corporativo.

\section{Teoria da Agência}

A influência da teoria da agência remonta a razões históricas, envolvendo escândalos de má gestão em grandes empresas multinacionais, que suscitaram em 1992, no Reino Unido, o relatório do Cadbury Commitee sobre as causas de vários eventos relacionados à gestão oportunista de empresas.

A base explicativa da teoria da agência assumida neste artigo parte da clássica abordagem de Jensen e Meckling (1976) considerada seminal nos estudos sobre governança, apesar da relevância dos trabalhos anteriores. Depois desse trabalho foram desenvolvidos inúmeros estudos empíricos e novas modelagens teóricas (e.g. EISENHARDT, 1989; GLAESER, 2003).

Nessa perspectiva, a firma é definida como uma ficção legal que serve como foco para um processo complexo no qual os objetivos conflitantes dos indivíduos são trazidos ao equilíbrio dentro de uma estrutura de relações contratuais. A firma, então, 
representa uma maneira de integrar de forma eficiente os objetivos conflitantes dos diversos participantes de um contexto contratual legal. Ou seja, o comportamento da firma é semelhante ao do mercado, sendo resultado de um complexo processo de equilíbrio (JENSEN e MECKLING, 1976).

O modelo de comportamento humano que sustenta a teoria da agência (resourceful, evaluative, maximizing model) foi descrito por Jensen e Meckling (1994) sob quatro premissas: os indivíduos (1) são avaliadores (i.e. preocupam-se com diversos fatores, como prestígio), estão dispostos a fazer substituições (trade-offs) e têm preferências transitivas; (2) têm necessidades ilimitadas (i.e. preferem de forma insaciável uma maior quantidade de bens que avaliam positivamente); (3) são maximizadores (i.e. buscam a maior utilidade possível; no entanto a satisfação é limitada por fatores como normas e conhecimento restrito, o que os leva a refletirem sobre custos de aquisição de informações e conhecimento necessário para avaliação das alternativas); e (4) são engenhosos (i.e. são criativos e respondem às mudanças do ambiente, adaptando-se e criando novas oportunidades).

Um dos pressupostos fundamentais da teoria da agência é que existe uma relação conflituosa entre objetivos das partes que compõem um conjunto de contratos. A teoria da agência, em suma, refere-se ao relacionamento existente entre principal e agente, no qual uma pessoa (principal) contrata outra (agente) para executar algo que envolva a delegação de tomada de decisão e autoridade. Disso decorre a relação de agência, definida como: "[...] um contrato sob o qual uma ou mais pessoas (o(s) principal(is)) empregam outra pessoa (agente) para executar em seu nome um serviço que implique a delegação de algum poder de decisão ao agente" (JENSEN e MECKLING, 1976, p. 308, tradução nossa).

Assume-se que haja divergências de interesses entre o principal e o agente porque cada um possui diferente função utilidade. O alicerce da teoria da agência está no pressuposto de que não se pode maximizar uma função utilidade que não seja sua, pois o comportamento está fundamentado no conjunto de preferências e objetivos da própria pessoa. Quando o agente gerencia recursos de propriedade do principal tendo como referência a maximização da sua função utilidade e não a do principal, tal situação se denomina problema de agência (JENSEN e MECKLING, 1976). Ou seja, advém da incongruência entre o comportamento do agente desejado pelo principal e o comportamento de fato do agente.

De acordo com Jensen e Meckling (1976), além da natureza humana utilitarista e racional, que leva o agente a maximizar a sua função utilidade, a inexistência de contrato completo capaz de assegurar que o agente vise a atender os interesses do principal também leva ao desalinhamento entre os interesses do principal e do agente.

Fama e Jensen (1983) esclarecem que os contratos também atribuem aos agentes as fases do processo de decisão. Para tanto, os autores dividem a decisão de forma que se desdobre em quatro etapas, quais sejam: iniciação, ratificação, implementação e monitoramento. Explicam que a iniciação e a implementação devem ser combinadas na função gerenciamento da decisão; e a ratificação e o monitoramento, na função gerenciamento do controle, visto que tais conjuntos são, em geral, desempenhados pelas mesmas pessoas. Para os autores, um sistema eficiente de controle implica a separação entre as fases iniciação e implementação (gerenciamento da decisão) e ratificação e monitoramento (gerenciamento do controle), pois dessa forma o processo visa a reduzir ou controlar os problemas de agência.

Fama e Jensen (1983) complementam sugerindo a delegação das funções de decisão. Os autores discutem o caráter complexo das organizações, uma vez que o conhecimento específico necessário à tomada de diferentes decisões está disperso entre diversos agentes. Assim sendo, a delegação das funções de decisão aos agentes com mais conhecimento específico relevante traz potenciais benefícios em decisões de melhor qualidade. No entanto, a distribuição das decisões aos agentes gera problemas de agência, haja vista a natureza racional do comportamento humano e a inexistência de contrato perfeito, pressupostas pela teoria da agência. Assim, é sugerida a repartição das funções de gerenciamento e de controle entre diferentes agentes como mecanismo para reduzir esses problemas.

Jensen e Meckling (1995) forneceram uma explicação mais detalhada sobre a necessidade de descentralização do processo decisório, baseando-se nos conhecimentos específico e geral. Quando o conhecimento é importante no processo de tomada de decisão, há vantagens em combinar a autoridade de decisão e o conhecimento específico relevante. Essa combinação pode se dar pela transferência do conhecimento ou pela transferência dos direitos de decisão.

Tendo em vista a impossibilidade de transferir totalmente o conhecimento específico ao tomador de decisão, a maioria dos direitos de decisão deve ser delegada aos que detêm o conhecimento específico. Isso implica desenvolver sistemas de controle para reduzir os problemas de agência. 
Para Jensen e Meckling (1995), as organizações resolvem esses problemas estabelecendo regras internas do jogo que fornecem um sistema de particionamento dos direitos de decisão para os agentes da organização e um sistema de controle que forneça a mensuração e a avaliação do desempenho, bem como um de recompensa e punição. Jensen (1983) já havia proposto que os contratos entre os agentes e a entidade legal especificam as regras dentro da organização incluindo essas três dimensões: distribuição dos direitos de decisão entre os agentes, sistema de avaliação do desempenho e sistema de recompensas.

A eficiência organizacional provém, então, da combinação entre esses dois sistemas (JENSEN, 1983; JENSEN e MECKLING, 1995). Entretanto, é impossível eliminar os problemas de agência. O principal deles incorre em custos de agência para alinhar os interesses do agente aos seus. Jensen e Meckling (1976) definem custo de agência como a soma de gastos com monitoramento do principal sobre as atividades dos agentes; gastos do agente para mostrar ao principal que suas atividades não são prejudiciais a ele; e perdas residuais decorrentes de divergências entre as decisões dos agentes e aquelas que maximizariam o bem-estar do principal, apesar do uso do monitoramento pelo principal e do alinhamento pelo agente.

Para Jensen e Meckling (1976), os custos de agência surgem em qualquer situação, envolvendo esforço cooperativo entre duas ou mais pessoas, mesmo que não exista uma clara relação agente-principal. Na mesma direção Eisenhardt (1989) argumenta que a relação de agência ocorre em diversas relações, mesmo as informais. Para a autora, o contrato (instrumento por meio do qual o principal encarrega o agente de atuar em seu nome) é uma ilustração metafórica da relação de agência, pois tanto nos acordos explícitos como nos implícitos está presente a relação de agência.

Como solução para amenizar os problemas da agência, Jensen e Meckling (1976) sugerem auditorias, sistemas de monitoramento e controle formais e informais, restrições orçamentárias, políticas de remuneração e sistema de incentivo, restrições contratuais etc. Todos os mecanismos, naturalmente, envolvem custos de agência.

Fama (1980) complementa que o mercado de capital e o mercado de trabalho dos dirigentes de alto nível exercem papel de mecanismo de controle das ações oportunistas dos agentes, para o que sugere que o grau de divergência do comportamento de dirigente de alto nível em relação ao comportamento de maximização do valor das organizações é limitado pela existência de um mercado de trabalho de dirigentes, que reflete sua reputação (capital humano), tendo como proxy o sucesso ou fracasso da empresa da qual é dirigente, e, também, por um mercado de capital no qual é atribuído preço aos direitos negociáveis da empresa. Jensen (1993) amplia este argumento sugerindo quatro forças de controle operantes na organização que amenizam os problemas de agência. Além dos mecanismos internos, que ele denomina como controle interno exercido pelo Conselho de Administração, há mecanismos externos (vinculados a fatores exógenos à organização): mercado de capital; sistema legal, político e regulatório; e mercado de produtos e fatores - que abarca o mercado de trabalho de dirigentes de alto nível, conforme proposto por Fama (1980).

Acrescenta-se que a estrutura de propriedade tem sido tratada como fator relevante sobre os principais conflitos de interesse e problemas de agência a serem enfrentados. Em situações de estrutura proprietária dispersa, o conflito de interesse ocorre entre os acionistas individuais e os executivos; e em estruturas concentradas, entre acionistas majoritários (detentores de controle) e minoritários (acionistas dispersos). No primeiro caso, por hipótese, os acionistas dispersos têm menos incentivo ao monitoramento e os executivos têm mais acesso à informação sobre os negócios (assimetria informacional), o que lhes permite tomar decisões que os favoreçam em detrimento dos acionistas. No segundo, os acionistas majoritários, com determinada concentração da propriedade (direito a voto), passam a perseguir, por hipótese, benefícios privados à custa dos demais investidores. Supõe-se a premissa coeteris paribus para ambas as hipóteses.

Há evidências empíricas que corroboram essas hipóteses. Shleifer e Vishny (1997) destacam-se evidenciando que a presença de acionistas controladores aumenta a relação custo-benefício do monitoramento, pois têm tanto interesse na maximização do valor quanto no poder de voto para terem seus interesses respeitados; e também Bebchuk (1999), que evidenciou forte relação entre estrutura proprietária, padrões de governança e benefícios privados do controle.

Ilustra-se essa distinção pelo estudo de Coffee (2005) a respeito da influência da concentração acionária sobre o tipo de fraude. $\mathrm{O}$ autor apurou que, em ambientes empresariais de estrutura de propriedade pulverizada, comum nos países anglo-saxões, o principal problema a ser combatido é a manipulação dos resultados financeiros pelos executivos (diante da assimetria de informação) a fim de aumentar sua remuneração pessoal; ao passo que, em ambientes com estrutura proprietária concentrada, comum nos países nipo-germânicos e emergentes, o principal problema é a extração de benefícios privados de controle pelos acionistas majoritários. Pode-se, então, concluir que, sendo a forma de fraude diferente em distintas estruturas proprietárias, os problemas de agência tendem a ser diferentes. 
Acrescenta-se que o problema de agência é generalizado, uma vez que o problema de induzir um agente a se comportar como se ele estivesse maximizando o bem-estar do principal faz-se presente em todas as organizações e em todos os esforços cooperativos (GLAESER, 2003).

\section{Governança Corporativa no Terceiro Setor}

Ao sobrepor os conceitos de governança ao contexto do terceiro setor, é importante considerar nessa aproximação algumas distinções e alinhamentos. Assim, assume-se neste artigo que o doador "contrata" a ONG para o desenvolvimento de projetos de interesse mútuo e que, no entanto, a ONG pode não agir no melhor interesse do doador. Como consequência, há o estabelecimento de contrato no qual o doador delega certo nível de autoridade à ONG para tomar decisões quanto à execução das atividades do projeto objeto da contratação.

Dessa relação, aceita-se que surjam preocupações derivadas de conflitos de agência, especificamente quanto à segurança de que as ações dos gestores da ONG estão alinhadas aos interesses do doador, haja vista que ambas as partes, no relacionamento principal-agente, buscam maximizar sua função utilidade (JENSEN e MECKLING, 1976). Nesse sentido, é preciso instituir mecanismos que amenizem os problemas de agência, observando-se que, em menor ou maior grau, eles sobrecarregam os custos de agência.

\section{Pressupostos subjacentes à teoria da agência}

A teoria da agência enfatiza que, no estabelecimento do contrato, considera-se que agente e principal atuam segundo comportamento racional e motivados por interesses próprios. Não se apoia, porém, exclusivamente nas diferenças de motivação e objetivos entre principal e agente, mas também em premissas de assimetria de informação, distinta tolerância ao risco e diferente horizonte de planejamento entre as partes, que implicam a racionalidade limitada dos agentes econômicos (EISENHARDT, 1989).

A ONG dispõe de informações sobre requisitos, restrições e resultados de suas atividades relacionadas ao projeto para o qual recebeu recursos em doação, que podem não ser conhecidas pelo doador (LACRUZ, MOURA e ROSA, 2019), configurando-se a assimetria de informação. Essa assimetria cria condições para a ação oportunista, seja pelo registro de informações imprecisas, incompletas, tendenciosas, ainda que involuntariamente, ou mesmo fraude. Acrescenta-se que o oportunismo, na teoria da agência, pode se manifestar ex-ante ou ex-post ao momento da contratação, traduzindo-se nos problemas de seleção adversa e de risco moral respectivamente (WILLIAMSON, 1987). Isso é válido para as entidades do terceiro setor, no qual se incorrem em custos ex-ante (custos de estruturação, salvaguardas etc.) e também ex-post (renegociações, aditivos contratuais, monitoramento da observância dos acordos, avaliação de prestação de contas parciais etc.).

Além disso, pode-se esperar que o doador seja mais tolerante ao risco do que a ONG, uma vez que se espera que consiga diversificar mais seu portfólio de doação, podendo ser indiferente ao risco não sistemático, ao passo que da ONG se pode esperar comportamento de aversão ao risco, por ter mais dificuldade de diversificar seu portfólio de projetos e por estarem o recebimento de recursos em doação e sua credibilidade atrelados ao seu desempenho em relação ao contrato - em analogia ao sucesso/fracasso da empresa como proxy de reputação dos dirigentes de alto nível, conforme proposto por Fama (1980). Assim, as partes da relação de agência têm diferente tolerância a riscos.

Por último, também se aceita a premissa de incompatibilidades de horizonte de planejamento, mas de forma inversa no contexto do terceiro setor em relação ao assumido como regra geral para organizações empresariais com fins lucrativos. Defende-se que a transitoriedade dá-se não em relação ao agente, mas ao principal.

O doador aloca esforços em ações cujos efeitos dão-se no horizonte de tempo do contrato de doação, ao passo que a ONG tem uma relação de permanência com a firma, na qual os objetos da contratação (i.e. o projeto) estão por vezes relacionados aos objetivos de longo prazo. Ou seja, os doadores estão mais preocupados com os resultados da firma durante o tempo do contrato e a ONG está mais preocupada com os resultados do seu portfólio de projetos presentes e futuros. Assim, a ONG tende a fazer o planejamento dos projetos segundo horizontes que ultrapassam os limites do contrato de doação, principalmente quando tais projetos estão relacionados a programas da instituição; ao passo que os doadores estão mais interessados no planejamento do projeto para o qual fizeram a doação (LACRUZ e CUNHA, 2018; LACRUZ, CUNHA, MOURA et al., 2019). 
Também a avaliação de desempenho, extracontratual, tende a se apoiar em diferentes métricas devido ao distinto horizonte de planejamento (LACRUZ, MOURA e ROSA, 2019), pois as métricas de desempenho da ONG levam em consideração seu coletivo de projetos, ao passo que as do doador pode ter o viés de objetivos de curto prazo. Assume-me, então, que a firma tem vida finita e que, no ambiente do terceiro setor, o agente (ONG) considera o valor da firma como uma série infinita de ações e o principal (doador) limita-se em grande medida aos fluxos de ações no interstício do contrato.

Nesse contexto, a exemplo de Tondolo, Bitencourt e Tondolo (2016) e Lacruz, Moura e Rosa (2019), propõe-se que projetos no ambiente do terceiro setor podem ser vistos como organizações temporárias. Apoiando-se na definição de Lundin e Söderholm (1995), para os quais as organizações temporárias são desacopladas de atividades organizacionais passadas e futuras, a temporalidade e o consequente desacoplamento podem explicar a relação inversa, no contexto do terceiro setor, da premissa de incompatibilidade de horizonte de planejamento entre principal e agente.

Assim, como consequência da relação de agência, surgem os problemas de agência e a consequente ocorrência de custos de agência para sua minimização, por exemplo, a elaboração de contratos mais complexos e a instituição de mecanismos de monitoramento mais intensos. Nesse encadeamento a governança surge com o objetivo de atenuar os problemas de agência.

\section{Mecanismos de governança}

A discussão sobre governança demanda uma análise específica da natureza organizacional do objeto de análise. Então, é preciso inicialmente alinhar os conceitos de governança, geralmente associados às organizações empresariais, às entidades do terceiro setor, neste estudo tomadas pelas associações e fundações privadas sem fins lucrativos.

\section{Sistema de incentivo}

Uma primeira distinção relevante diz respeito ao sistema de incentivo como mecanismo de alinhamento de interesses entre principal e agente. A hipótese dos sistemas de incentivo concedidos aos executivos é de que a forma de remuneração pode induzir o comportamento (FAMA, 1980; JENSEN e MECKLING, 1976). Isso parece válido tanto para o ambiente de organizações empresariais quanto de entidades do terceiro setor. Porém as possibilidades são maiores no ambiente de organizações empresariais, cujos contratos de incentivo podem assumir uma variedade de formas, como distribuição de ações, opções de compra de ações ou outras formas de remuneração variável (FAMA, 1980); ao passo que no terceiro setor as possibilidades são limitadas (e.g. a remuneração, a qualquer título, vinculada ao superávit cessaria o benefício constitucional das imunidades tributárias conferido às ONGs, conforme art. 2ㅇ, § 3으, II, da Lei no 10.101/2000).

Jegers (2009) e Van Puyvelde, Caers, Bois et al. (2012) argumentam que essa solução não é muito plausível para o contexto do terceiro setor devido à dificuldade de mensuração de desempenho. Para Mendonça e Machado Filho (2004), é inexistente o alinhamento via benefícios pecuniários no terceiro setor, sob a premissa de não haver expectativa desse tipo de retorno pelos executivos, pois sua atuação profissional é motivada pela adesão à causa, o que já havia sido sugerido por Rose-Ackerman (1987). Nesse sentido, Handy e Katz (1998) sugerem que salários mais baixos podem gerar uma autosseleção entre os gestores sem fins lucrativos, pois irá atrair gestores que estão mais comprometidos com a causa da organização do que com o salário; fenômeno explicado por Jegers (2008) baseado no trade-off entre remuneração (financial health) e preferências (own preferences): "[...] a inutilidade de um salário mais baixo é compensada pelo efeito de utilidade de fazer algo altruísta" (JEGERS, p. 45, tradução nossa).

Existe algum suporte empírico sobre sistemas de incentivo em ONGs (e.g. BALSAM e HARRIS, 2014) que indica que a maior parte dos critérios de desempenho organizacional não é estatisticamente significante quando relacionada à remuneração dos gestores. No entanto, há vieses que limitam a generalização dos resultados, pois se apoiam em análises transversais, enquanto uma abordagem longitudinal seria mais adequada para inferir relações entre mudança de desempenho e mudança de remuneração, como adverte Jegers (2009). Além disso, nem sempre consideram a possibilidade de recompensas monetárias.

Em sentido contrário, defende-se que, apesar de limitado, é possível o alinhamento via sistema de incentivo pecuniário. 0 ordenamento legal brasileiro proíbe a distribuição de lucros em ONGs. Porém não impede que se estabeleça remuneração variável. Supor que executivos de ONGs tenham outras motivações não é inválido, mas que não sejam motivados por questões pecuniárias parece improvável no contexto atual. Nessa direção, o estudo Pesquisa salarial realizada pelo Grupo de Institutos, Fundações e Empresas (GIFE), revelou que 75\% das organizações associadas à Rede GIFE possuem um programa 
de remuneração variável, sendo o mais comum a bonificação por desempenho (GIFE, 2015). Por tudo isso se assume que as limitações relacionadas à remuneração no terceiro setor podem diminuir a importância dos sistemas de incentivo, mas não a excluem como instrumento desse tipo de sistema.

\section{Estrutura proprietária}

Outra distinção importante relaciona-se à estrutura proprietária, que no terceiro setor está relacionada à concentração de recursos por doadores. É de se esperar que haja ONGs com predomínio de recursos de doadores dispersos e outras com concentração de recursos em poucos doadores, da mesma forma que doadores possam concentrar em poucas ONGs suas doações. Tal qual no ambiente de organizações empresariais, em ONGs com predomínio de recursos de doadores dispersos pode haver comparativamente menos incentivo ao monitoramento por parte dos doadores do que em entidades com concentração de recursos em poucos doadores. Ou seja, não se pode descartar que a estrutura proprietária pode moderar o incentivo ao monitoramento por parte do principal em ONGs (ANDRÉS-ALONSO, CRUZ e ROMERO-MERINO, 2006; YETMAN e YETMAN, 2012).

Outro aspecto, ainda relacionado à estrutura proprietária, diz respeito aos direitos de propriedade: direito de decisão e direito ao fluxo de recursos. A condição "sem fins lucrativos", por definição, exclui o componente "distribuição de lucros". Nesse sentido, Glaeser (2003) e Fama e Jensen (1983) propõem que não há direitos residuais nas ONGs. Disso se poderia assumir ser mais adequado considerar a separação entre controle (principal) e gestão (agente) do que entre propriedade (principal) e gestão (agente). No entanto, ampliando o sentido do termo direito residual, pode-se complementar que os associados (associações) ou instituidores (fundações) são detentores de direitos residuais que necessariamente seriam reinvestidos no objeto social da ONG, visto que tal direito pode ser entendido como algo além da apropriação para si do lucro/superávit. Logo, há de se reconhecer que há custos de agência relacionados às perdas residuais, dos quais decorrem problemas de agência de natureza propriedade $x$ gestão também em ONGs.

\section{Conselho de administração}

O Conselho de Administração representa o órgão colegiado de deliberação encarregado de manter, na tomada de decisões, o direcionamento estratégico da entidade. É importante destacar que nas ONGs o Conselho de Administração não é um órgão obrigatório no Brasil (Lei n. 10.406/2002, capítulo II), ao contrário do que exige a Lei das Empresas de Sociedade Anônima. Além disso, é um órgão não remunerado. Ademais, as regras para estruturação do Conselho de Administração variam de estatuto para estatuto (art. 54, V, e 55 da Lei n.o 10.406/2002), não havendo um padrão legal, o que permite, por exemplo, que seja composto por apenas dois membros e que o sistema de eleição contemple membros vitalícios. Tudo isso reduz o papel de mecanismos de governança do Conselho de Administração, quando comparado com o de organizações empresariais.

Para Jensen (1993), numa perspectiva de governança das organizações empresariais, algumas das causas da falta de comprometimento dos conselhos têm recaído sobre seu tamanho, sua composição e sua independência. Em relação ao terceiro setor, pode-se acrescentar a ausência de remuneração e de regras para sua estruturação (MINDLIN, 2009). O tema Conselho de Administração talvez seja o mais estudado em pesquisas sobre governança no terceiro setor (RENZ e ANDERSSON, 2014). Estudos empíricos sobre esse setor têm sido feitos abordando a sua composição (e.g. ANDRÉS-ALONSO, AZOFRAPALENSUELA e ROMERO-MERINO, 2010), seu comportamento (e.g. BALDUCK, VAN ROSSEM e BUELENS, 2010), propondo índices de boas práticas de governança para conselhos (e.g. BOARDSOURCE, 2017), dentre outros aspectos. Os resultados, porém, não estão no mesmo diapasão.

Acrescenta-se, como aponta Mindlin (2009), que os membros do conselho são eleitos, muitas vezes, como forma de facilitar a captação de recursos e estabelecer contatos relevantes à ONG. Sobre isso, Andrés-Alonso, Azofra-Palenzuela e RomeroMerino (2010) não identificaram associação estatisticamente significativa entre o percentual de membros do Conselho de Administração com experiência em fundraising e eficiência alocativa ou administrativa. Já Harris, Petrovits e Yetman (2015), tomando o Conselho de Administração como construto, identificaram associação positiva com total de doações recebidas. E Callen, Klein e Tinkelman (2003) evidenciaram associação estatisticamente significativa entre a presença de um grande doador e eficiência organizacional. Sugeriram que a presença de grandes doadores no conselho pode ser um sinal para outros doadores sobre a "qualidade" da organização, o que levaria ao aumento do volume de doações. 


\section{Conselhofiscal}

O Conselho Fiscal é um órgão de fiscalização da administração contábil e financeira. Não é um órgão obrigatório no Brasil para as organizações empresariais nem para as sem fins lucrativos. Destaca-se que, de acordo com Silveira (2010), no contexto das organizações empresariais, tal conselho inexiste nos mercados mais avançados, como Estados Unidos, Reino Unido, Alemanha e França, nos quais o comitê de auditoria é responsável pelo monitoramento da administração contábil e financeira da organização.

No Brasil, caso seja instalado, organizações empresariais têm constituição e competência definidas em lei (Lei n.o 6.404/1976). Entidades sem fins lucrativos não possuem ordenamento legal próprio, este será regido conforme previsto no estatuto da entidade.

A presença de um conselho fiscal pode estar amparada no entendimento de que ele representa uma linha adicional de defesa do interesse do principal - ainda que sobrecarregado de custos de agência. Nesse sentido, Fontes-Filho e Bronstein (2016) identificaram a presença do Conselho Fiscal em 93,7\% das 157 ONGs brasileiras que compuseram sua amostra. No mesmo sentido, o Instituto Brasileiro de Governança Corporativa, no Guia das melhores práticas para organizações do terceiro setor: associações e fundações, recomenda como boa prática de governança a previsão em estatuto social do Conselho Fiscal (IBGC, 2016). Ou seja, por tomar o doador como principal na relação de agência, assume-se que o Conselho Fiscal aja em sua defesa, uma vez que suas ações se direcionam à fiscalização dos atos da administração, em especial à verificação da conformidade das obrigações legais e estatutárias (LAMB, 2002; IBGC, 2016), dentre elas os termos dos contratos de doação. Ou seja, a presença do Conselho Fiscal pode amenizar o conflito de agência decorrente da relação contratual estabelecida entre o doador (principal) e a ONG (agente) no processo de doação.

\section{Mercado de doações}

Glaeser (2003) e Mendonça e Machado Filho (2004) defendem que o mercado de doações no terceiro setor equivale, como mecanismo externo de governança, ao mercado de capitais para empresas de capital aberto. 0 mercado de capitais reflete, pelo valor das ações nas bolsas de valores, o desempenho atual da empresa e a expectativa esperada pelos investidores de desempenho futuro. Isso pode ser entendido como incentivo para que acionistas majoritários - nas empresas de capital concentrado - ou conselhos de administração - nas de capital disperso - monitorem as ações dos gestores. O que, portanto, tem efeito de incentivo sobre os gestores para aumentar o valor das ações. Apesar dos referidos autores reconhecerem que, no mercado de doações, como não há acionistas, inexiste a possibilidade de aquisições hostis. Defendem que a (i) liberdade dos doadores em aplicar seus recursos nas ONGs que consideram mais adequadas e o (ii) risco de perda de reputação da ONG, no caso de gestão ineficiente ou indevida, são elementos de regulação do mercado de doações.

Sobre isso, acerca da liberdade dos doadores em aplicar seus recursos, complementa-se que o argumento parece mais válido em um mercado de doações desvinculadas (sem restrições), no qual prevalece a liberdade do doador na alocação dos seus recursos em doação. Já em um mercado de doações vinculadas (com restrições), a discricionariedade do doador é geralmente limitada por um instrumento de chamada pública de apoio a projetos. Além do que, é formado, em analogia ao mercado de capitais, por diversas "bolsas de valores", representadas pelos editais de apoio a projetos, formando um mercado absolutamente fragmentado e sem padrões que permitam a comparação a priori entre entidades no Brasil, em analogia aos níveis diferenciados de governança, como o da BM\&FBOVESPA no Brasil. Depura-se, desse modo, neste estudo, o mercado de doações como vinculado e desvinculado.

Talvez o segundo argumento de Mendonça e Machado Filho (2004) - sobre o risco de perda de reputação da entidade no caso de gestão ineficiente ou indevida - esteja mais bem alinhado à dimensão mercado de fatores e produtos (ignorada pelos autores) do que à de mercado de capitais - tratadas por Jensen (1993) na sua discussão a respeito do papel do mercado como mecanismo de controle externo das organizações e na abordagem de Fama (1980) sobre a separação entre propriedade e controle da organização.

Em relação à influência da governança na decisão sobre doação de doadores institucionais para ONGs, Kitching (2009) encontrou associação positiva entre entidades do terceiro setor auditadas por uma big five e por meio do volume de doações recebidas. Aggarwal, Evans e Nanda (2012) evidenciaram relação positiva entre a estatura do Conselho de Administração da entidade e volume de doações; Saxton, Neely e Guo (2014) identificaram relação positiva entre transparência, medida por divulgação na web, e doações. Harris, Petrovits e Yetman (2015), por sua vez, evidenciaram relação positiva da "qualidade" da 
governança, composta por sete dimensões (board, management, policies, access, audit, executive compensation e minutes), com o volume de doações.

Em complemento a essa discussão, Andrés-Alonso, Cruz e Romero-Merino (2006), em análise sobre a influência da participação de doadores institucionais públicos na eficiência de ONGs espanholas, identificaram que a participação de um doador institucional ativo está positivamente relacionada a uma maior eficiência da entidade, em termos de eficiência técnica e alocativa. Yetman e Yetman (2012) evidenciaram que ONGs com mais restrições impostas por seus doadores relatam suas informações financeiras com mais precisão. Isso evidencia, portanto, a influência do doador no monitoramento das ações das entidades em adição ao papel do mercado de doações como mecanismo de governança.

Em arremate, aponta-se que, para lidar com as restrições do mercado de doações, as ONGs adotam, cada vez mais, abordagens do mercado privado com fins lucrativos, levando ao que Salamon (1997) denominou "marketization" do setor sem fins lucrativos. A lógica desse argumento, sob o pressuposto de que (i) as ONGs precisam de recursos para sobreviver e (ii) existem requisitos com os quais devem se conformar para receberem doações, é de que as ONGs são levadas a agir em aderência aos que controlam os recursos no mercado de doação. São, assim, conduzidas a práticas e procedimentos prevalecentes em organizações que constituem o mercado de doação, dentre eles as práticas de governança (LACRUZ, MOURA e ROSA, 2019).

No Brasil, um dos primeiros a discutirem o tema foi Tenório (1999), cujo estudo aponta que a "profissionalização" das entidades do terceiro setor objetiva mais sua sobrevivência organizacional do que a maior efetividade das suas ações como agentes sociais; assim, por detrás do espectro do mercado, há uma racionalidade que submete o terceiro setor à lógica de base mercantil. No Brasil, esse fenômeno foi estudado também empiricamente. Silva e Aguiar (2011), por exemplo, avaliaram a influência de pressões do ambiente institucional sobre práticas de avaliação de atividades de entidades do terceiro setor, concluindo que a dinâmica estabelecida entre agentes, instituições e ONGs orienta-se, predominantemente, por uma racionalidade instrumental.

\section{Sistema político, legal e regulatório}

O sistema político, legal e regulatório é um mecanismo externo de governança que delimita a segurança jurídica. Um contexto legal genérico e de pouca fiscalização efetiva como o do terceiro setor no Brasil está longe de criar um mecanismo efetivo do comportamento dentro das organizações. No entanto, para se beneficiarem de incentivos tributários, distinções e recebimento de recursos em doação da administração pública, as entidades do terceiro setor devem atender a determinados requisitos adicionais, e isso traz alguma efetividade como mecanismo de controle externo ao seu sistema político, legal e regulatório.

Acerca dos incentivos tributários, a Constituição Federal torna imune a impostos as instituições de educação e assistência social (art. 150, VI, c) e isenta de contribuições sociais as entidades beneficentes de assistência social (art. 195, §7ㅇ). Para que as entidades usufruam de imunidade, o Código Tributário Nacional (CTN) estabelece no art. 14 os seguintes requisitos: não distribuição de lucro, proibição de remessa de receitas ao exterior e livros de escrituração contábil em perfeita ordem e clareza (há regulação específica sobre impostos de competência da União, Estados e Municípios, como a legislação sobre o imposto de renda, que amplia os requisitos de acesso à imunidade). As entidades que não cumprirem tais requisitos podem ter sua imunidade suspensa (art. 14, §1ㅇ do CTN). Para ter acesso à isenção de contribuições sociais, foram igualmente estabelecidos requisitos (art. 29 e 30 da Lei n. 0 12.101/2009).

Destaca-se, em complemento, que ONGs podem pleitear a obtenção de determinados títulos, qualificações e certificações no âmbito do controle institucional do Estado, com destaque para qualificação como Organização Social (OS), instituída pela Lei n.o 9.637/1998; qualificação como Organização da Sociedade Civil de Interesse Público (OSCIP), instituída pela Lei n.을 9.790/1999; e o Certificado de Entidade Beneficente de Assistência Social (CEBAS), instituído pela Lei n.o 12.101/2009. Essas distinções conferem benefícios às entidades do terceiro setor e, em contrapartida, impõe-lhes obrigações adicionais.

Por fim, ressalta-se que parcerias envolvendo transferência de recursos para entidades do terceiro setor pela administração pública resultam em obrigações adicionais, como a eleição de um quadro dirigente (Art. 34, V da Lei n.o 13.019/2014), o que se configura como mecanismo externo de governança na dimensão do sistema político, legal e regulatório. 


\section{CONCLUSÕES}

Este estudo contribui para o campo da teoria da agência quando aplicada às relações no terceiro setor, uma vez que a estruturação da governança em ONGs sob a perspectiva dessa teoria permitiu formular relações que complementam suas generalidades, contribuindo para o melhor entendimento da sua aplicação no contexto do terceiro setor.

Ao longo deste estudo, foram alinhados os pressupostos e conceitos da teoria de agência ao ambiente do terceiro setor. Pode-se destacar a proposição de que o pressuposto da incompatibilidade de horizontes de planejamento entre principal (doador) e agente (ONG) ocorre de forma inversa no terceiro setor ao assumido como regra geral para organizações empresariais, sob o entendimento de que o doador esteja mais preocupado com os resultados da firma durante o tempo do contrato de doação (ou seja, os resultados do projeto do qual é sponsor) e que a ONG esteja mais preocupada com os resultados do seu portfólio de projetos presentes e futuros. Em outras palavras, propõe-se que o agente (ONG) considere o valor da firma como uma série infinita de ações e o principal (doador), os fluxos de ações no interstício do contrato.

Também se realça a proposição de custos de agência relacionados às perdas residuais no ambiente do terceiro setor, dos quais decorrem problemas de agência de natureza propriedade $x$ gestão. E, ainda, a depuração do mercado de doações em doações vinculadas e desvinculadas.

Diante disso emergem como agenda de pesquisa estudos sobre como se manifesta na governança das ONGs o mercado de doação como mecanismo externo de controle. Considerando que (1) a premissa de diferentes horizontes de tempo no terceiro setor implica transitoriedade do doador em relação à ONG, pois tem suas ações limitadas à relação contratual; (2) as ONGs desenvolvem suas ações por meio de projetos (DIALLO e THUILLIER, 2004; MARQUES, RODY, REINA et al., 2015), cujos recursos são captados no mercado de doação vinculada; (3) o processo de marketization (SALAMON, 1997) imputa às ONGs práticas prevalentes nas organizações que compõem o mercado de doação: pode-se questionar: dada a transitoriedade do doador em relação à ONG, o mercado de doação age, em complemento ao sistema político legal e regulatório, reconfigurando a governança nessas organizações? Ou ainda: o mercado de doação medeia a relação entre o sistema político legal e regulatório e a governança em ONGs?

Ademais, apesar de o tema governança ter sido muito explorado em estudos aplicados a ONGs (e.g. GAZLEY e NICHOLSONCROTTY, 2018), em especial em relação às dimensões Conselho de Administração (e.g. REDDY, LOCKE e FAUZI, 2013) e transparência (e.g. HASKI-LEVENTHAL e FOOT, 2016); há indícios de conexões não exploradas, por exemplo: o papel do projeto vinculado à doação como antecedente, moderador ou mediador da influência da governança no recebimento de doações e o possível papel moderador da qualificação da ONG (e.g. OSCIP) na relação entre governança e recebimento de doações num ambiente de baixa regulação, como no Brasil. Da mesma forma, quanto à ambiência, os espaços mostram-se diferenciados entre as próprias associações e fundações, uma vez que estas são fiscalizadas pelas Curadorias das Fundações, órgão do Ministério Público de cada município (art. 66 da Lei n.o 10.406/2002): do que se poderia avaliar se a governança manifesta-se de forma diferente entre distintas naturezas jurídicas das entidades do terceiro setor.

Importa registrar, neste encadeamento, que pesquisas baseadas em dados secundários são constrangidas no Brasil (MARQUES, RODY, REINA et al., 2015). Um projeto promissor no País é o FUNDATA (http://www.fundata.org.br), que mantém banco de dados sobre as organizações da sociedade civil sem fins lucrativos, de natureza jurídica fundacional - a base de dados, porém, não está disponível para download. Outra iniciativa é o Mapa das OSCs (http://mapaosc.ipea.gov.br), cujos dados, por ora, são limitados às relações das entidades do terceiro setor com o governo federal - a base de dados está disponível para download. Esse tipo de iniciativa é importante para o fortalecimento do setor, pois lança luz ao segmento servindo de orientação à sociedade. 


\section{REFERÊNCIAS}

AGGARWAL, R. K.; EVANS, M. E.; NANDA, D. Nonprofit boards: size, performance and managerial incentives. Journal of Accounting and Economics, v. 53, n. 1-2, p. 466-487, 2012.

ALDASHEV, G.; VERDIER, T. Goodwill bazaar: NGO competition and giving to development. Journal of Development Economics, v. 91, n. 1, p. 48-63, 2010, 48-63.

ANDRÉS-ALONSO, P.; AZOFRA-PALENZUELA, V.; ROMERO-MERINO, $M$. E. Beyond the disciplinary role of governance: how boards add value to Spanish foundations. British Journal of Management, v. 21, n. 1, p. 100-114, 2010.

ANDRÉS-ALONSO, P.; CRUZ, N. M; ROMERO-MERINO, M. E. The Governance of nonprofit organizations: empirical evidence from nongovernmental development organizations in Spain. Nonprofit and Voluntary Sector Quarterly, v. 35, n. 4, p. 588-604, 2006.

ÁVILA, L. A. C.; BERTERO, C. O. Governança no terceiro setor: Um estudo de caso em uma fundação de apoio universitário. Revista Brasileira de Gestão de Negócios, v. 18, n. 59, p. 125-144, 2016.

BALDUCK, A.; VAN ROSSEM, A.; BUELENS, M. Identifying competencies of board members of community sports clubs. Nonprofit and Voluntary Sector Quarterly, v. 39, n. 2, p. 213-235, 2010.

BALSAM, S.; HARRIS, E. E. The impact of CEO compensation on nonprofit donations. Accounting review, v. 89, n. 2, p. 425-450, 2014.

$B E B C H U K, L$. A rente protection theory of corporate ownership and control. Working paper n. 7203. National Bureau of Economic Research, Cambridge, MA, 1999. Disponível em: <http://www.nber. org/papers/w7203>. Acesso em: 03 jan. 2019.

BOARDSOURCE. Leading with intent: 2017 national index of nonprofit board practices. 2017. Disponível em: <https://leadingwithintent. org/wp-content/uploads/2017/11/LWI-2017.pdf>. Acesso em: 03 jan. 2019.

CALLEN, J. L.; KLEIN, A.; TINKELMAN, D. Board composition, committees, and organizational efficiency: the case of nonprofits. Nonprofit and voluntary sector quarterly, v. 32, n. 4, p. 439-520, 2003.

COFFEE, J. C. A theory of corporate scandals: why the U.S. and Europe differ. Oxford review of economic policy, v. 21, n. 2, p. 198-211, 2005.

DANGINO, E. Civil society in Latin America. In: EDWARDS, M. (Org.). The Oxford handbook of civil society. Oxford: Oxford University Press, 2011.

DIALLO, A.; THUILLIER, D. The success dimensions of international development projects: the perceptions of African project coordinators. International journal of project management, v. 22, n. 1, p. 19-31, 2004.

EIKENBERRY, A. M.; KLUVER, J. D. The marketsization of the nonprofit sector: civil society at risk?. Public administration review, v. 64, n. 2, p. 132-140, 2004.

EISENHARDT, K. M. Agency Theory: an Assessment and Review. Academy of management review, v. 14, n. 1, p. 57-74, 1989.

FAMA, E. F. Agency problems and the theory of the firm. Journal of Political Economy, v. 88, n. 2, p. 288-307, 1980.

FAMA, E. F.; JENSEN, M. C. Separation of ownership and control. Journal of Law and Economics, v. 26, n. 2, p. 301-325, 1983.
FERNANDES, R. C. Privado porém público: o terceiro setor na América Latina. Rio de Janeiro: Relume-Dumará, 1994.

FERNANDES, R. C. O que é o terceiro setor. In: IOSCHPE, E. B. (Org.). Desenvolvimento social sustentado. São Paulo: Paz e Terra, 1997.

FONTES-FILHO, J. R.; BRONSTEIN, M. M. Governance solutions in listed companies and not-for-profit organizations. Annals of Public an Cooperative Economics, v. 87, n. 3, p. 391-410, 2016.

GAZLEY, B.; NICHOLSON-CROTTY, J. What drives good governance? A estructural equation model of nonprofit board performance. Nonprofit and Voluntary Sector Quarterly, v. 47, n. 2, p. 262-285, 2018. 262-285.

GLAESER, E. L. The governance of not-for-profit organizations. Chicago: The University of Chicago Press, 2003. (Introduction)

GREILING, D.; STÖTZER, S. Performance accountability as a driver for changes in nonprofit-government relationships: an empirical insight from Austria. Voluntas, v. 26, n. 5, p. 1690-1717, 2015.

GRUPO DE INSTITUTOS FUNDAÇÕES E EMPRESAS. Pesquisa salarial. São Paulo: GIFE, 2015.

HANDY, F.; KATZ, E. The wage differential between nonprofit institutions and corporations: getting more by paying less? Journal of Comparative Economics, v. 26, n. 2, p. 246-261, 1998.

HARRIS, E.; PETROVITS, C. M.; YETMAN, M. H. The effect of nonprofit governance on donations: evidence from the revised form 990. Accounting Review, v. 90, n. 2, p. 579-610, 2015.

HASKI-LEVENTHAL, D.; FOOT, C. The relationship between disclosure and household donations to nonprofit organizations in Australia. Nonprofit and Voluntary Sector Quarterly, v. 45, n. 5, p. 992-1012, 2016.

HASNAN, S. et al. Corporate governance factors affecting donation: evidence from charitable organizations in Malaysia. International Journal of Economics and Financial issues, v. 6, n. 6, p. 149-153, 2016.

INSTITUTO BRASILEIRO DE GEOGRAFIA E ESTATÍSTICA - IBGE. Estatísticas do cadastro central de empresas 2016. Rio de Janeiro: IBGE, 2018.

INSTITUTO BRASILEIRO DE GOVERNANÇA CORPORATIVA - IBGC. Guia das melhores práticas para organizações do terceiro setor: associações e fundações. São Paulo: IBGC, 2016.

INSTITUTO DE PESQUISA ECONÔMICA APLICADA - IPEA. Perfil das organizações da sociedade civil no Brasil. Brasília: IPEA, 2018.

JEGERS, M. Managerial economics of non-profit organizations. Routledge: Routledge, 2008.

JEGERS, M. "Corporate" governance in nonprofit organizations: a nontechnical review of the economic literature. Nonprofit Management \& Leadership, v. 20, n. 2, p. 143-164, 2009.

JENSEN, M. C. Organization theory and methodology. Accounting review, v. 58, n. 2, p. 319-339, 1983.

JENSEN, M. C. The modern industrial revolution, exit, and the failure of internal control systems. Journal of Finance, v. 48, n. 3, p. 831-880, 1993. 
JENSEN, M. C.; MECKLING, W. H. Theory of the firm: Managerial behavior, agency costs and ownership structure. Journal of Financial Economics, v. 3, n. 4, p. 305-360, 1976.

JENSEN, M. C.; MECKLING, W. H. The Nature of man. Journal of Applied Corporate Finance, v. 7, n. 2, p. 4-19, 1994.

JENSEN, M. C.; MECKLING, W. H. Specific and general knowledge and organizational structure. Journal of Applied Corporate Finance, v. 8, n. 2, p. 251-274, 1995.

KITCHING, K. Audit value and charitable organizations. Journal of Accounting and Public Policy, v. 28, n. 6, p. 510-524, 2009.

LACRUZ, A. J.; CUNHA, E. Project management office in nongovernmental organizations: an ex post facto study. Revista de Gestão, v. 25, n. 2, p. 212-227, 2018.

LACRUZ, A. J. et al. Project Management Office in the Non-Governmental Organization as a driver of sustainable competitive advantage: a dynamic capabilities approach. In: PERIS-ORTIZ, M.; FERREIRA, J. J. M.; MERIGÓ, J. M. (Org.). Knowledge, innovation and sustainable development in organizations. Switzerland: Springer, 2019.

LACRUZ, A. J.; MOURA, R. L.; ROSA, A. R. Organizing in the shadow of donors: how donations market regulates the governance practices of sponsored projects in non-governmental organizations. Brazilian Administration Review, v. 16, n. 13, p. 1-23, 2019.

$L A M B, R$. Modelagem para uma investigação da efetiva função do conselho fiscal nas sociedades por ações brasileiras. 2002. Porto Alegre: EA/UFRGS.

LUNDIN, R. A.; SÖDERHOLM, A. A theory of the temporary organization. Scandinavian Journal of Management, v. 11, n. 4, p. 437-455, 1995.

MARQUES, B. A. et al. Terceiro setor: panorama das tendências de 1998 a 2013 por meio de um estudo bibliométrico. Enfoque: Reflexão Contábil, v. 34, n. 2, p. 71-89, 2015.

MENDONÇA, L. R. DE; MACHADO FILHO, C. A. P. Governança nas organizações do terceiro setor: considerações teóricas. Revista de Administração da USP, v. 39, n. 4, p. 302-308, 2004.

MINDLIN, S. E. A governança de fundações e institutos empresariais: um estudo exploratório. 2009. Tese (Doutorado em Administração) Faculdade de Economia, Administração e Contabilidade, Universidade de São Paulo, São Paulo, 2009.

POZORSKI, C. Social venture partners: "venture capital" grantmaking in practice. Grantmanship Center Magazine, p. 24-26, Fall 2000.

REDDY, K.; LOCKE, S.; FAUZI, F. Relevance of corporate governance practices in charitable organisations. International Journal of Managerial Finance, v. 9, n. 2, p. 110-132, 2013.
RENZ, D. O.; ANDERSSON, F. O. Nonprofit governance: a review of the field. In: CORNFORTH, C.; BROWN, W. A. (Orgs.). Nonprofit governance: innovative perspectives and approaches. New York: Routledge, 2014.

ROSE-ACKERMAN, S. Ideals versus dollars: donors, charity managers and government grants. Journal of political economy, v. 95, n. 4, p. 810-823, 1987.

RYAN, W. P. The new landscape for nonprofits. Harvard business review, v. 77, n. 1, p. 127-136, 1999.

SALAMON, L. M. Holding the Center: America's Nonprofit Sector at a Crossroads. New York: Foundation Center, 1997.

SAXTON, G. D.; NEELY, D. G.; GUO, C. Web disclosure and the market for charitable contributions. Journal of Accounting and Public Policy, v. 33, n. 2, p. 127-144, 2014.

SHLEIFER, A.; VISHNY, R. W. A survey of corporate governance. Journal of finance, v. 52, n. 2, p. 737-783, 1997.

SILVA, C. E. G. Gestão, legislação e fontes de recursos no terceiro setor brasileiro: uma perspectiva histórica. Revista de Administração Pública, Rio de Janeiro, v. 44, n. 6, p. 1301-1325, 2010.

SILVA, C. E. G.; AGUIAR, A. C. Avaliação de atividades no terceiro setor de Belo Horizonte: da racionalidade subjacente às influências institucionais. Organizações \& Sociedade, v. 18, n. 56, p. 35-36, 2011.

SILVEIRA, A. D. M. DA. Governança corporativa no Brasil e no mundo. Rio de Janeiro: Elsevier, 2010.

SMITH, S. R. Nonprofits and public administration: reconciling performance management and citizen engagement. The american Review of Public Administration, v. 40, n. 2, p. 129-152, 2010.

TENÓRIO, F. G. Um espectro ronda o terceiro setor: o espectro do mercado. Revista de Administração Pública, Rio de Janeiro, v. 33, n. 5, p. 85-102, 1999.

TONDOLO, R. da R. P.; BITENCOURT, C. C.; TONDOLO, V. A. G. Social capital in temporary inter-organizational projects. Desenvolvimento em Questão, v. 14, n. 33, p. 363-388, 2016.

VAN PUYVELDE, S. et al. The governance of nonprofit organizations: integrating agency theory with stakeholder and stewardship theories. Nonprofit and Voluntary Sector Quarterly, v. 41, n. 3, p. 431-451, 2012.

WILLIAMSON, O. E. The economic institutions of capitalism. New York: The Free Press, 1987.

YETMAN, M. H.; YETMAN, R. J. The effects of governance on the accuracy of charitable expenses reported by nonprofit organizations. Contemporary Accounting Research, v. 29, n. 3, p. 738-767, 2012.

Adonai José Lacruz

ORCID: https://orcid.org/0000-0003-1575-3788

Doutor em Administração pela Universidade Federal do Espírito Santo (UFES); Professor no Instituto Federal de Educação, Ciência e Tecnologia do Espírito Santo (IFES), campus Viana; Professor no Programa de Pós-Graduação em Administração da Universidade Federal do Espírito Santo (UFES), Vitória - ES, Brasil. E-mail: adonai.lacruz@ifes.edu.br 